\title{
Pelatihan Pembuatan Media Pembelajaran Inovatif Kelompok Guru Sekolah Dasar Negeri Melong Mandiri 4 Kota Cimahi
}

\author{
Yusep Ahmadi $\mathbf{F}^{1^{*}}$, Gida Kadarisma ${ }^{2}$ \\ IKIP Siliwangi ${ }^{1,2}$ \\ yusep-ahmadi-f@ikipsiliwangi.ac.id*, gidakadarisma@ikipsiliwangi.ac.id
}

\begin{abstract}
Learning in primary schools largely depends on the role of the teacher, because at the elementary school age students still tend to need teachers as a source of knowledge and direction in solving a problem. Learning in partner primary schools has problems relating to instructional media especially Indonesian language learning media and mathematics. This stimulus community partnership program aims to provide solutions to problems in the partner school of Public Elementary School of Melong Mandiri 4 Cimahi so that the teachers become skilled at designing and making learning media. These problems include the unavailability of adequate learning media; the teacher's skill is not optimal in designing and making innovative learning media. The solution offered in this program is training in designing and making innovative and interesting learning media on Indonesian language and mathematics lessons, namely takalintar media, geoboard, serial images, paper puppets, KPK boards and FPB, for ICT-based media using Powerpoint and Geogebra. This training was conducted using lecture and discussion methods as well as the practice of making instructional media. The results achieved from this activity are there is an increase in the skills of teachers in making innovative learning media by $40 \%$.
\end{abstract}

Keywords: Training; Innovative Learning Media; Primary school.

\begin{abstract}
Abstrak
Pembelajaran di sekolah dasar sebagian besar bergantung pada peran guru, karena pada usia sekolah dasar siswa masih cenderung memerlukan guru sebagai sumber pengetahuan dan pengarah dalam menyelesaikan sebuah masalah. Dalam proses pembelajaran seperti itu media pembelajaran menjadi aspek penting dalam mencapai hasil pembelajaran yang optimal. Pembelajaran di sekolah dasar mitra memiliki masalah yang berkaitan dengan media pembelajaran khususnya media pembelajaran bahasa Indonesia dan matematika. Program kemitraan masyarakat stimulus ini bertujuan untuk memberikan solusi atas permasalahan di sekolah mitra SD Melong Mandiri 4 Cimahi agar guru-gurunya menjadi terampil merancang dan membuat media pembelajaran. Masalah tersebut di antaranya belum tersedianya media pembelajaran yang memadai; belum optimalnya keterampilan guru dalam merancang dan membuat media pembelajaran yang inovatif. Solusi yang ditawarkan dalam program ini adalah pelatihan perancangan dan pembuatan media pembelajaran inovatif dan menarik pada pelajaran bahasa Indonesia dan matematika, yaitu media takalintar, geoboard, gambar berseri, wayang kertas, papan KPK dan FPB, untuk media berbasis ICT menggunakan Powerpoint dan Geogebra. Pelatihan ini dilaksanakan dengan metode ceramah dan diskusi serta praktik pembuatan media pembelajaran. Hasil yang dicapai dari kegiatan ini
\end{abstract}


adalah terdapat peningkatan keterampilan guru-guru dalam membuat media pembelajaran inovatif sebesar $40 \%$.

Kata Kunci: Pelatihan; Media Pembelajaran Inovatif; Sekolah Dasar.

\section{A. PENDAHULUAN}

Sekolah Dasar merupakan jenjang sekolah yang sangat berperan dalam membangun pondasi pengetahuan anak. Oleh karena itu, guru sekolah dasar harus memliki kemampuan dalam memberikan pembelajaran yang sesuai dengan tahap kognisi anak. Sebagaimana yang diungkapkan Piaget (Rusefendi, 2006) usia 7 sampai sekitar 11/12 tahun merupakann tahap operasi kongkret. Pada tahap tersebut anak memerlukan media kongkret dalam belajar. Oleh karena itu, media pembelajaran menjadi sangat penting dalam pembelajaran tahap ini. Ketersediaan dan inovasi media pembelajaran di tingkat sekolah dasar merupakan sebuah keniscayaan dalam tercapainya hasil pembelajaran yang baik. Hal itu pu tidak terlepas dari kemampuan gurudalam mebelajarkan siswa siswinya. Salah satu kemampuan guru yang perlu dikembangkan dan ditingkatkan yaitu kemampuan membuat dan menggunakan media pembelajaran yang inovatif dan efektif.

Media pembelajaran merupakan hal penting dalam keberhasilan proses pembelajaran. Hal itu sejalan dengan yang dijelaskan Brown (Sanjaya, 2014) bahwa media pembelajarann merupakn komponen yang harus diperhatikan guru dalam merancang sistem pembelajaran. Yandari dan Kuswaty (2017) bahwa peranan media pembelajaran sangat penting dalam upaya peningkatan kemampuan pemahaman konsep matematis peserta didik. Bahkan media pembelajaran dapat menjadi penentu hasil suatu pembelajaran. Dalam konteks sekolah dasar media pembelajaran terhadap anak anak sekolah dasar perlu dirancang dan diwujudkan sesuai dengan kebutuhan siswa dan semangat zaman. Berdasarkan hasil wawancara kepada siswa sekolah mitra, kami menyimpulkan minat belajar siswa kurang. Hal ini dikarenakan pembelajaran di dalam kelas kurang menarik terutama dalam pembelajaran matematika dan bahasa indonesia. Mengingat mata pelajaran tersebut sangat dominan untuk sekolah dasar.

Hasil observasi yang telah kami lakukan di sekolah mitra belum adanya media pembelajaran yang inovatif yang dapat menumbuhkan minat belajar siswa. Media media yang telah tersedia cenderung berupa gambar-gambar yang bagi sebagaian siswa kurang menimbulkan semangat belajar. Di sekolah dasar pada dasarnya lebih dominan mempelajari bahasa Indonesia dan Matematika khususnya untuk kelas 1 sampai kelas 4. Kami sebagai dosen yang mempunyai kempotensi di bidang tersebut akan mengembangkan dan membuat mediamedia pembelajaran yang inovatif dan lebih memiliki sifat interaktif.

Pengembangan media pembelajaran di sekolah dasar khususnya media pembelajaran bahasa Indonesia dan matematika menjadi sangat penting. Hal itu disebabkan bahw a bahasa merupakan hal paling mendasar yang selalu menaungi berbagai aspek kehiduman manusia. Memijam istilah Heidegger (dalam Latif, 2013) bahwa bahasa adalah the house of being 'rumah kehidupan'. Menurut Heidegger manusia menjadi hampir mustahil 
keluar dari bahasanya. Pembelajaran bahasa di sekolah dasar menjadi aspek yang sangat penting. Pembelajaran bahasa akan berpengaruh terhadap pembelajaranpembelajaran matakuliah lain. Kecerdasan berbahasa seseorang dapat menentukan pula kecerdasannya dalam memahami dan mereflesikan pelajaran-pelajaran yang lain.

Sejalan dengan itu, pemeblajaran matematika pun menjadi sangat prinsip keberadaannya. Matematika di sekolah dasar mempelajari berbagai hal-hal dasar yang akan diterapkan siswa dalam kehidupan sehari-hari, semisal berhitung, mengukur jarang, mengukur volume, dan menentukan luas dan keliling suatu bidang datar, guru harus menciptakan pembelajaran matematika yang interaktif dan menyenangkan (Safitri, Hartono, Somakim, 2017). Hal-hal tersebut merupakan hal mendasar yang harus dipahami siswa dengan cermat dan mudah dan hal itu dapat terwujud dengan efektik ketika media pembelajaran yang digunakan bersifar inovatif dan interaktif. Media pembelajaran dalam Matematika biasanya dikembangkan sesuai dengan objek kajiannya sehingga memudahkan untuk dipelajari (Nuraini dkk, 2017).

Terwujudnya pembelajaran yang efektif melalui media pembelajaran yang menarik dan inovatif merupakan cita-cita pendidikan kita. Adanya media pada proses belajar mengajar, diharapkan dapat membantu guru dan siswa dalam pembelajran lebih visual, interaktif, menarik, mudah dan cepat dimengerti (Wibowo, 2012). Hasil pembelajaran yang diharapkan tentunya akan mendapat hasisl yang maksimal sejauh ikhtiar kita dalam merancang dan menggunakan media pembelajaran yang efektif dan menarik para siswa untuk belajar. Karakteristik dan kemampuan masing-masing media perlu diperhatikan oleh guru agar mereka dapat memilih media mana yang sesuai dengan kondisi dan kebutuhan (Nurryna,2009). Pada tataran inilah pengabdian yang akan kami laksanakan menunjukkan urgensinya. PKMS ini perlu dilaksanakan demi terciptanya masyarak sekolah khususnya guru dan siswa menjadi tentram dan efektif dalam melaksanakan pembeajaran melalui media pembelajaran yang inovatif.

Tujuan program PKMS ini adalah meningkatkan keterampilan guru-guru SD N Melong Mandiri 4 Kota Cimahi dalam merancang dan membuat media pembelajaran yang inovatif yang sesuai dengan tema-tema pembelajaran di sekolah dasar khususnya yang berkenaan dengan pelajaran bahasa Indonesia dan Matematika.

Permasalahan yang kami akan berikan solusi adalah khusus berkait masalah media pembelajaran mata pelajaran bahasa Indonesia dan matematika. Bahasa indonesia dan matematikan merupakan mata pelajaran yang sangat penting di sekolah dasar. Pembelajaran bahasa yang gagal akan berdampak secara sistemik terhadap pembelajaran-pembelajaran yang lain. Hal itu disebabkan bahwa bahasa merupakan tatanan pokok dalam pembelajaran khususnya di sekolah dasar. Begitupun dengan matematika yang menjadi kunci untuk belajar tentang kebutuhan -kebutuhan mendasar dalam kehidupan sehari-hari seperti belajar menghitung muali dari penjumlahan, pengurangan, perkalian, pembagian, menghitung sudut, berat, volume, dan jarak. Hal-hal tersebut adalah kebutuhan manusia yang paling dasar dalam berkehidupan.

Hasil observasi awal yang memperlihatkan media pembelajaran bahasa dan matematika yang kurang dan belum di sekolah mitra akan diberikan sebuah solusi melalui pelatihan perancangan dan pembuatan media pembelajaran inovatif di 
sekolah dasar kepada guru yang dikhususkan pada pelajaran bahasa Indonesia dan matematika.

Hasil studi pustaka di antaranya menyatakan bahwa media digital komik dalam proses pembelajaran dapat meningkatkan minta belajar ( Sukmanasa dkk., 2017). Berkait dengan media digital, guru akan diberi pelatihan cara membuat media digital dengan memanfaatkan program program sederhana seperti power point. Program ini di sekolah mitra belum diberdayakan secara maksimal untk dapat menjadi media pemberdayaan yang inovatif dan menarik minat siswa dalam belajar.

\section{B. PELAKSAAAN DAN METODE}

Metode pelaksanaan PKMS ini berupa pelatian pembuatan media pembelajaran, lokasi dari kegiatan ini di SDN Melong Mandiri 4 Kelurahan Melong Kecamatan Cimahi Selatan dengan jumlah peserta sebanyak 20 peserta, diawal dan diakhir kegiatan guru diberi angket keterampilan dalam membuat media pembelajaran dengan jumlah 21 pernyataan, untuk mengukur peningkatan keterampilan setelah dan sebelum program dilaksanakan. Adapun tahapan dalam kegiatan pengabdian ini adalah :

1. Survei dan Analisis masalah.

Survei dan analisis masalah merupakan langkah pertama yang dilaksanan untuk mengetahui permasalahan atau kendala pembelajaran di sekolah mitra. Pada tahap ini kami melaksanakan observasi ke kelas sebanyak tiga kali dan melakukan wawancara terhadap siswa dan guru.

2. Perumusan masalah dan pengembangan solusi

Berdasarkan hasil analisis masalah dapat disimpulkan bahwa di sekolah mitra terdapat masalah dalam pembelajaran, yaitu pemanfaatan media pembelajaran yang belum optimal dan kurang kreatif dalam menumbuhkan minat belajar siswa. Solusi yang dilaksanakan secara umum merupakan proses pelatihan pembuatan media pembelajaran inovatif yang disesuaikan dengan berbagai tema pembelajaran di sekolah dasar. Berbagai media pembelajaran menggunakan bahan baku yang mudah di dapat di toko seperti, papan, tripleks, kertas, karton dan lain-lain. Selain itu, gurujuga dilatih untuk membuat media pembelajaran memanfaatkan software powerpoint dan geogebra.

3. Pelaksanaan PKMS berupa pemberian pelatihan kepada guru dilaksanakan dengan metode ceramah, diskusi dan praktik langsung membuat media pembelajaran. Dengan materi : Pelatihan Penggunaan software Geogebra, Gambar Berseri, Pembuatan Takalintar, Pembuatan Wayang Kertas, Power Point Pecahan, Salindia Powerpoint Gambar bergerak dan bersuara, Papan KPK dan FPB, Powerpoint Gambar dan Bagan, Pembuatan Geoboard, Komik digital.

\section{HASIL DAN PEMBAHASAN}

Pelaksanaan PKMS Kelompok Guru SDN Melong Mandiri 4 Kecamatan Cimahi Selatan Pelatihan Pembuatan Media Pembelajaran Inovatif ini dilaksanakan dalang rentang waktu 24 Juni 2019 s.d. 16 Juli 2019. Dalam pelaksanaan kegiatan tersebut dilakukan kegiatan pelatihan membuat 10 jenis media pembelajaran yang berkaitan dengan kompetensi matematika dan bahasa Indonesia. Penyajian pelatihan ini bersifat tematik dan materinya disesuaikan dengan tema yang terdapat pada kurikulum 2013 untuk sekolah dasar. 
Pelaksanaan kegiatan ini dilaksanakan di gedung SD N Melong Mandiri 4 Cimahi yang bertempat di wilayang kompleks Melong Green Garden kelurahan Melong Kecamatan Cimahi Selatan Kota Cimahi. Dalam pelaksanaan kegiatan ini guru guru pada walnya diberi pengetehauan secara umum mengenai media pembelajaran kemudian guru mendapatkan pelatihan pembuatan media pembelajaran dengan berbagai bahan dan alat yang sudah disiapkan oleh tim pengabdi. Guru-guru melaksanakan praktik pembuatan media pembelajaran inovatif dengan 10 jenis materi dan tema yang sesuai dengan kurikulum 2013 sekolah dasar.

\section{Pelatihan 1 : Geogebra}

Pelatihan 1 yaitu penggunaan software geogebra pada mata pelajaran matematika. Dalam kegiatan ini dijelaskan terlebih dahulu mengenai software geogebra dan hal-hal yang perlu diperhatikan dalam menggunakan software.

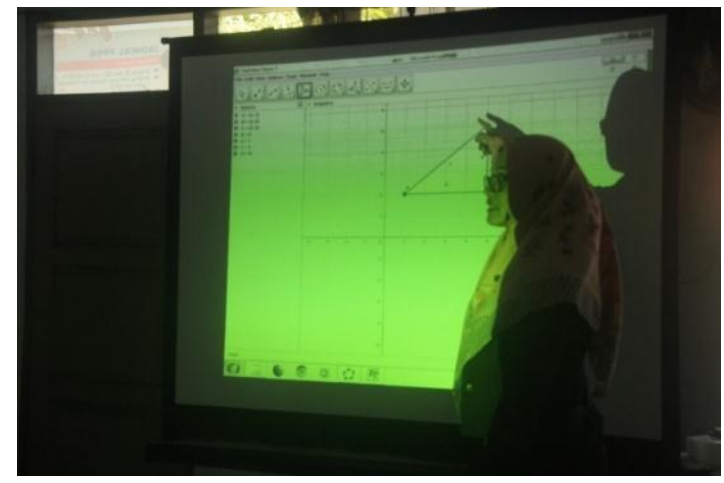

Gambar 1. Pelatihan Geogebra

Pada Gambar 1 Pemateri sedang menerangkan mengenai penggunaan dasar software geogebra, pada awal kegiatan guruguru masih kesulitan mengoperasikan software namun dengan arahan dari pelatih, mereka mulai terbiasa dan antusias dalam menggunakan software.

\section{Pelatihan 2: Gambar Berseri}

Pada Pelatihan media mata pelajaran bahasa Indonesia, dalam kegiatan ini dilaksanakan perancangan dan pembuatan media pembelajaran gambar berseri, pembuatan media ini bertujuan untuk mengembangkan dan meningkatkan kemampuan menyimak dan mengarang siswa. Media ini dapat terapkan pada pembelajaran kelas II dan III SD.

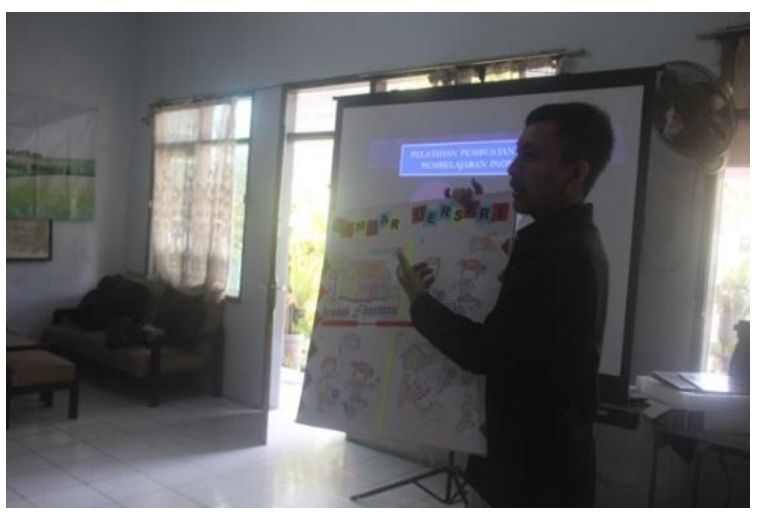

Gambar 2. Pelatih mendemonstrasikan Media Gambar Berseri

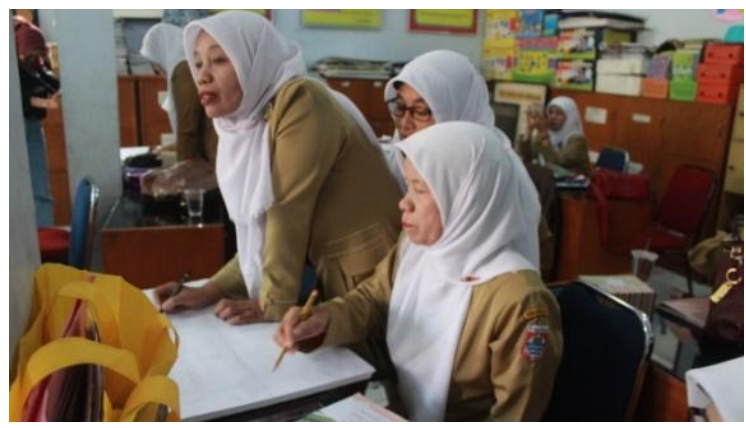

Gambar 3. Peserta sedang membuat Media Gambar Berseri

Pada Gambar 3. Peserta terlihat aktif dan kreatif dalam membuat media pembelajaran gambar berseri.

\section{Pelatihan 3: Takalintar}

Dalam kegiatan ini dijelaskan terlebih dahulu mengenai pentingnya media pembelajaran Takalintar dan hal-hal yang perlu diperhatikan dalam membuat media pembelajaran, kemudian dilaksanakan 
perancangan dan pembuatan media pembelajaran berupa "Takalintar". Media ini bertujuan untuk mempermudah siswa dalam mengenal konsep perkalian 3 angka.

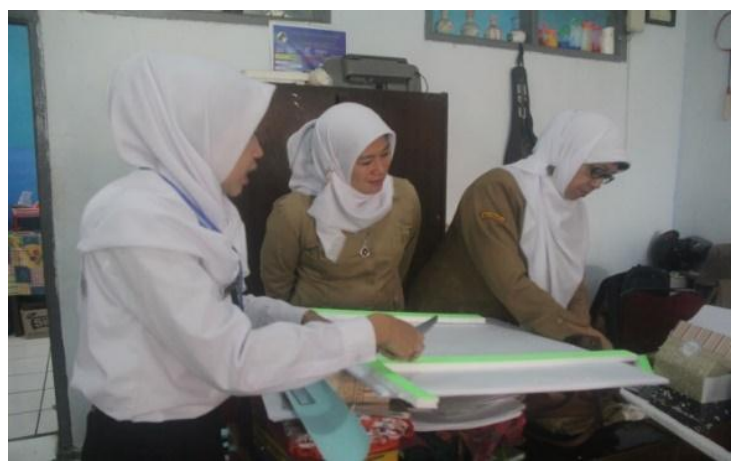

Gambar 4. Peserta membuat media takalintar

Pada Gambar 4. Terlihat peserta sedang bekerjasama tim dalm membuat media pembelajaran takalintar, peserta membuat sesuai kreasi mereka sendiri, tidak terpaku pada contoh media yang diberikan

\section{Pelatihan 4 : Wayang Kertas}

Dalam kegiatan ini dilaksanakan perancangan dan pembuatan media pembelajaran berupa wayang kertas, media ini bertujuan untuk meningkatkan kemampuan berbicara siswa. Media ini dapat diterpakan pada pembelajaran kelas IV SD.

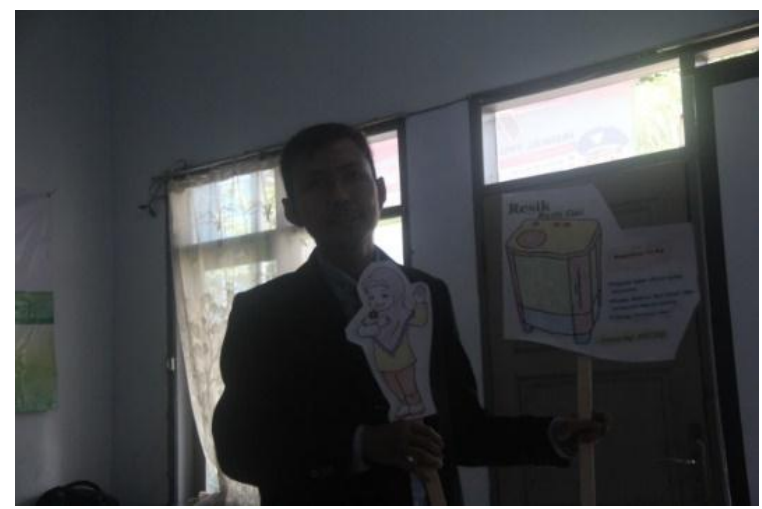

Gambar 5. Pelatih sedang mendemonstrasikan media wayang kertas

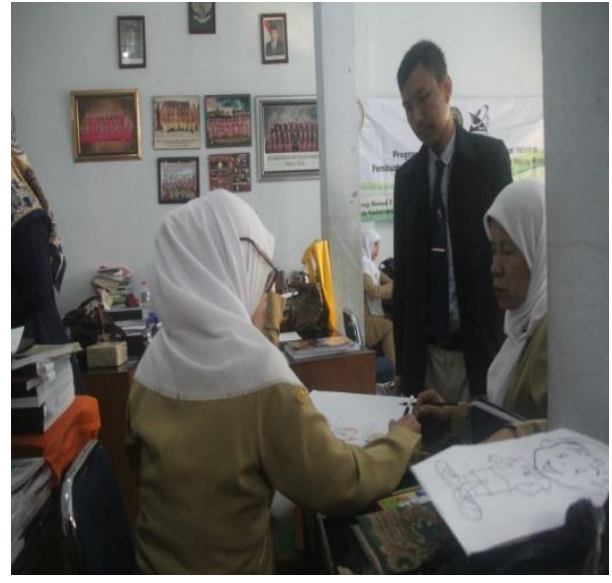

Gambar 6. Peserta sedang membuat wayang kertas

Pada Gambar 5. Pelatih/ penyuluh sedang mendemosntrasikan wayang kertas yang harus dibuat oleh guru-guru dengan tema berbeda.. Pada Gambar 6 dapat dilihat guru sedang aktif dan bekerjasama dalam tim membuat wayang kertas

\section{Pelatihan 5 :Powerpoint Pecahan}

Pelatihan 5 media mata pelajaran matematika, dalam kegiatan ini dilaksanakan pembuatan powerpoint interaktif dalam materi pecahan, diharapkan guru dapat membuat powerpoint yang menarik dalam menjelaskan konsep pecahan kepada siswa.

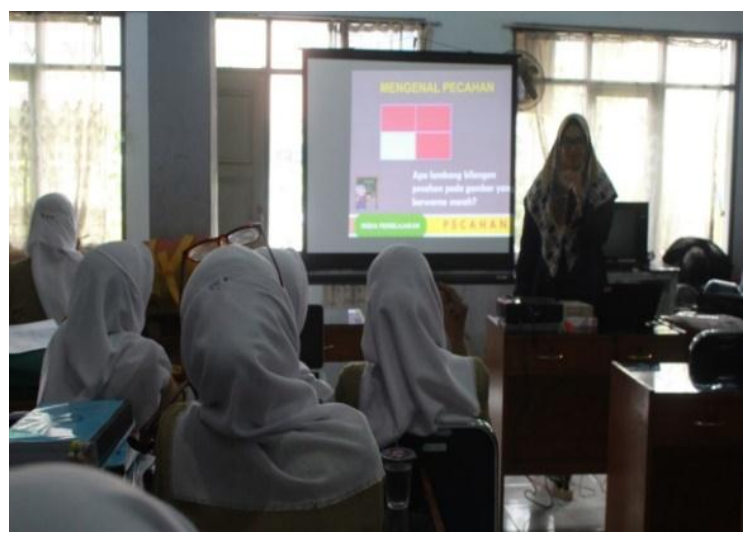

Gambar 7. Pemateri sedang mendemonstrasikan powerpoint pecahan

Pecahan adalah salah satu materi yang paling sulit dipelajari di Sekolah Dasar, 
dengan konsep yang tidak memadai siswa sulit dalam mempelajari pecahan, dengan powerpoint yang disajikan pada Gambar 7 guru merasa terbantu dalam mengajarkan pecahan pada siswa.

\section{Pelatihan 6 \& 7: Salindia Powerpoint Gambar Bergerak dan Bersuara serta Pelatihan bagan teks dan Gambar}

Pelatihan $6 \& 7$ media pada mata pelajaran bahasa Indonesia, dalam kegiatan ini dilaksanakan perancangan dan pembuatan media pembelajaran berupa salindia power point media ini bertujuan mengembangkan dan meningkatkan kemampuan mengarang dan menyimak siswa. Media ini diterapkan pada siswa kelas I dan II. Salindian berupa gambar bergerak dan bersuara bertema menjaga kebersihan lingkungan.

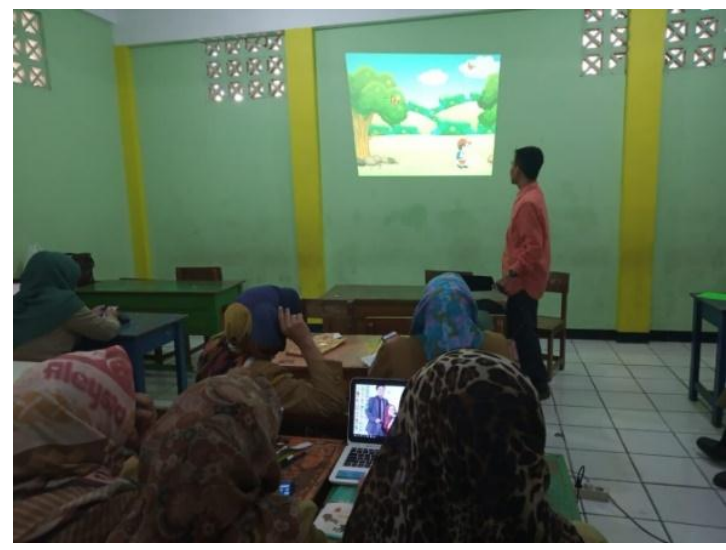

Gambar 8. Pelatihan powerpoint bergerak dan bersuara

Pada Gambar 8. Terlihat pemateri sedang mendemonstrasikan bagaimana membuat powerpoint bergerak dan bersuara dengan tema lingkungan

\section{Pelatihan 7 \& 8: Papan KPK/FPB dan Papan Berpaku}

Dalam kegiatan ini dilaksanakan perancangan dan pembuatan media pembelajaran "papan KPK dan FPB", pembuatan media ini bertujuan agar siswa lebih memahami dalam menyelesaikan soal KPK dan FPB.

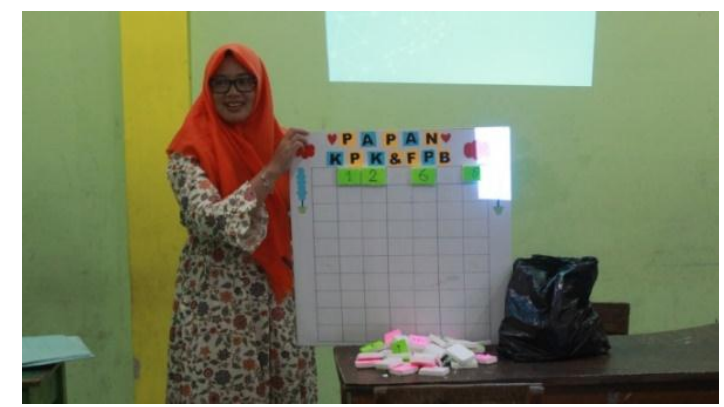

Gambar 9. Demonstrasi media papan KPK dan FPB

Pada Gambar 9. Pemateri sedang mendemonstrasikan penggunaan papan KPK dan FPB dan menjelaskan bagaimana cara membuatnya. Kemudian peserta dipersilahkan membuat media tersebut.

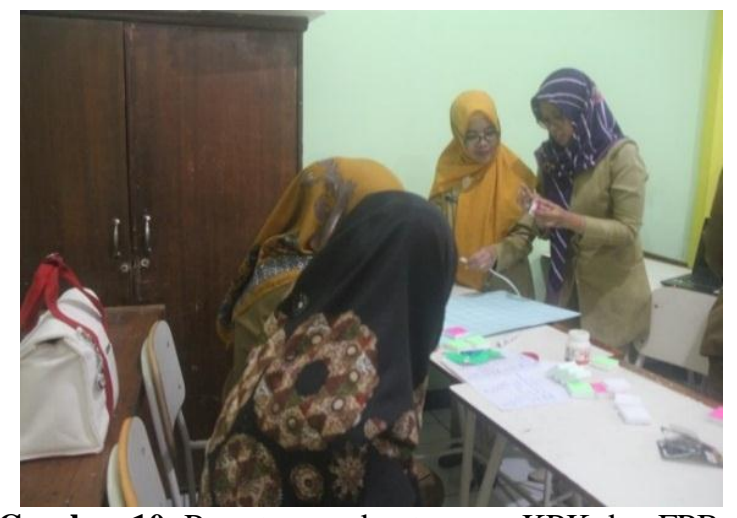

Gambar 10. Peserta membuat papan KPK dan FPB

Pada Gambar 10 peserta secara berkelompok membuat media papan KPK dan FPB

\section{Pelatihan 10: Komik Digital}

Dalam kegiatan ini dilaksanakan pembuatan komik digital yang berisi tentang cerita. Media pembelajaran ini bertujuan untuk mengembangkan dan meningkatkan kemampuan membaca. Media pembelajaran ini diterpkan pada siswa kelas III 


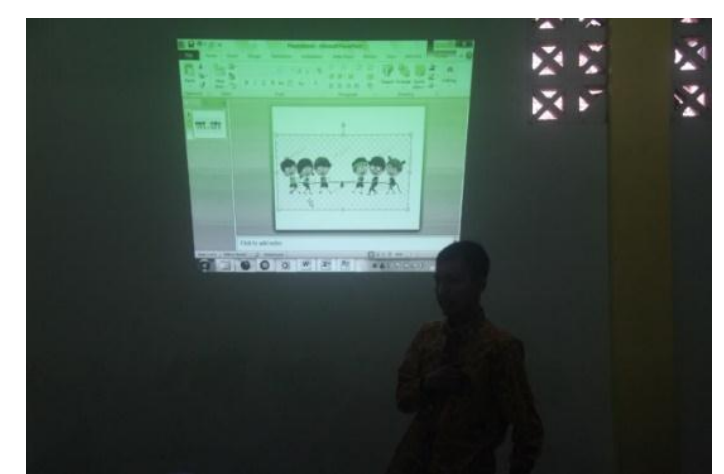

Gambar 11. Pemateri mempraktekan cara membuat komik digital

Pada Gambar 11 pemateri sedang menjelaskan bagaimana membuat komik digital dengan menggunakan powerpoint, peserta dengan antusias mengikuti instruksi dan mereka mendapat pengetahuan baru jika powerpoint dapat digunakan untuk membuat komik digital.

\section{Evaluasi Peningkatan Keterampilan Guru}

Salah satu hasil dari program kemitraan ini adalah meningkatnya keterampilan guru dalam membuat media pembelajaran inovatif, Aspek ini dapat dikur dari instrumen nontes yang diberikan pada guru di sekolah mitra pada awal dan akhir kegiatan, angket berupa Peningkatan Keterampilan Guru dalam membuat media pembelajaran inovatif, angket terdiri dari 21 pernyataan. Berdasarkan pengolahan dan analisis data disimpulkan bahwa keterampilan guru meningkat sebanyak $40 \%$.

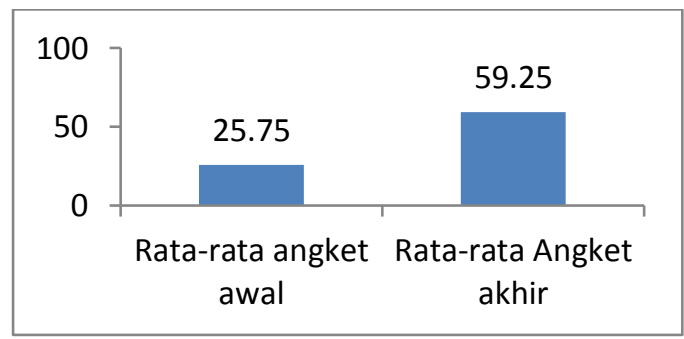

Gambar 12. Skor rata-rata angket awal dan angket Akhir $(\mathrm{SMI}=80)$.
Pada Gambar 12, dapat kita lihat bahwa ratarata angket awal sebesar 25,75 sedangkan ratarata angket akhir sebesar 59,25 dari skor maksimum ideal sebesar 80. Jika kita persentasekan terjadi kenaikan sebesesar $40 \%$. Berdasarkan analisis data dapat disimpulkan bahwa keterampilan guru pada sekolah mitra dalam membuat media pembelajaran meningkat. Dengan meningkatnya keterampilan guru dalam membuat media pembelajaran diharapkan guru dapat mengembangkan media

\section{Simpulan}

Hasil pengabdian ini dapat disimpulkan bahwa program PKMS ini telah meningkatkan keterampilan guru-guru dalam membuat media pembelajaran yang inovatif yang sesuai dengan tema-tema pembelajaran yang ada di sekolah dasar. Selain meningkatkan keterampilan, pengetahuan guru-gurupun menjadi meningkat terutama mengenai pemanfaatan program geogebra dan powerpoint sebagai media pembelajaran disekolah dasar. Kegiatan ini mendapatkan respon sangat baik dri guru-guru SD N Melong Mandiri 4 terlihat dengan antusiasme dan kehadiran para guru ketika kegiatan pelatihan berlangsung.

\section{Saran}

Dalam rangka mewujudkan pembelajaran yang interaktif dan inovatif perlu diadakan kembali kegiatan pengabdian semacam ini dengan frekuensi yang lebih lama dan materi yang lebih banyak. Hal tersebut dapat meningkatkan mutu keterampilan guru dalam proses pembelajaran dan diharapkan juga dapat meningkatkan hasil pembelajaran.

\section{Ucapan Terima Kasih}

Atas berlangsungnya kegiatan program kemitraan masyarakat stimulus (PKMS) ini, kami berterimakasih kepada Direktorat Riset dan Pengabdian pada Masyarakat (DRPM) 
Ristekdikti yang telah mendanai kegiatan ini, Sekolah mitra SDN Melong Mandiri 4 yang telah bersedia menjadi mitra dalam pengabdian ini, LPPM IKIP Siliwangi yang telah memfasilitasi kegiatan ini sehingga dapat berjalan lancer dan tepat waktu

\section{E. DAFTAR PUSTAKA}

Latif, Y. 2013. Menyemai karakter bangsa: budaya kebangkitan berbasis kesastraan. Jakarta: Kompas.

Nurryna, A. F. 2009. Pengembangan media pendidikan untuk inovasi pembelajaran. Speed-Sentra Penelitian Engineering dan Edukasi, 1(2).pp 1319.

Nur'aini, I. L., Harahap, E., Badruzzaman, F. H., \& Darmawan, D.2017. Pembelajaran Matematika Geometri Secara Realistis Dengan GeoGebra. Matematika, 16(2). pp 1-6.

Ruseffendi, E.T.2006. Pengantar kepada membantu guru mengembangkan kompetensinya dalam pengajaran matematika untuk meningkatkan CBSA. Bandung: Tarsito.

Safitri, M., Hartono, Y., \& Somakim, S. 2017. Pengembangan media pembelajaran matematika pokok bahasan segitiga menggunakan macromedia flash untuk siswa kelas VII SMP. Jurnal Pendidikan, 14(2), pp 62-72.

Sanjaya,W. 2017. Media komunikasi pembelajaran. Jakarta: Kencana Prenadamedia Grup.
Sukmanasa, Elly, Tustiyana W, Lina N. 2017. Pengembangan Media Pembelajaran Komik Digital Pada Mata Pelajaran Ilmu Pengetahuan Sosial Bagi Siswa Kelas V Sekolah Dasar Di Kota Bogor. Jurnal Pendidikan Sekolah Dasar (JPSD) UNTIRTA. 3 (2) pp 171-185.

Wibowo, E. J. 2012. Media Pembelajaran Interaktif Matematika untuk Siswa Sekolah Dasar Kelas IV. In SeruniSeminar Riset Unggulan Nasional Informatika.

Yandari, Indhira A V dan Maya K. 2017. "Penggunaan Media Monopoli Terhadap Peningkatan Kemampuan Pemahaman Konsep Matematis Peserta Didik Kelas V Sekolah Dasar". Jurnal Pendidikan Sekolah Dasar (JPSD) UNTIRTA 3(1) pp 10-16 